\title{
CARINA: nutrient data in the Atlantic Ocean
}

\author{
T. Tanhua ${ }^{1}$, P. J. Brown ${ }^{2}$, and R. M. Key ${ }^{3}$ \\ ${ }^{1}$ Leibniz-Institut für Meereswissenschaften, Marine Biogeochemie, Kiel, Germany \\ ${ }^{2}$ School of Environmental Sciences; University of East Anglia, Norwich, NR4 7TJ, UK \\ ${ }^{3}$ Atmospheric and Oceanic Sciences Program; Princeton, University, Princeton, NJ 08544, USA \\ Received: 15 June 2009 - Published in Earth Syst. Sci. Data Discuss.: 17 July 2009 \\ Revised: 23 October 2009 - Accepted: 30 October 2009 - Published: 6 November 2009
}

\begin{abstract}
Data on carbon and carbon-relevant hydrographic and hydrochemical parameters from previously non-publicly available cruise data sets in the Arctic, Atlantic and Southern Ocean have been retrieved and merged to a new database: CARINA (CARbon IN the Atlantic). These data have gone through rigorous quality control (QC) procedures to assure the highest possible quality and consistency. The data for most of the measured parameters in the CARINA data base were objectively examined in order to quantify systematic differences in the reported values, i.e. secondary quality control. Systematic biases found in the data have been corrected in the data products, i.e. three merged data files with measured, calculated and interpolated data for each of the three CARINA regions; Arctic Mediterranean Seas, Atlantic and Southern Ocean. Out of a total of 188 cruise entries in the CARINA database, 98 were conducted in the Atlantic Ocean and of these 84 cruises report nitrate values, 79 silicate, and 78 phosphate. Here we present details of the secondary QC for nutrients for the Atlantic Ocean part of CARINA. Procedures of quality control, including crossover analysis between cruises and inversion analysis of all crossover data are briefly described. Adjustments were applied to the nutrient values for 43 of the cruises in the Atlantic Ocean region. With these adjustments the CARINA database is consistent both internally as well as with GLODAP data, an oceanographic data set based on the World Hydrographic Program in the 1990s (Key et al., 2004). Based on our analysis we estimate the internal accuracy of the CARINA-ATL nutrient data to be: nitrate $1.5 \%$; phosphate $2.6 \%$; silicate $3.1 \%$. The CARINA data are now suitable for accurate assessments of, for example, oceanic carbon inventories and uptake rates and for model validation.
\end{abstract}

\section{Data coverage and parameter measured}

Repository-Reference: doi:10.3334/CDIAC/otg.CARINA.ATL.V1.0

Available at: http://cdiac.ornl.gov/oceans/CARINA/Carina_inv.html

Coverage: $60^{\circ} \mathrm{S}-75^{\circ} \mathrm{N} ; 80^{\circ} \mathrm{W}-34^{\circ} \mathrm{E}$

Location Name: Atlantic Ocean

Date/Time Start: 1977-10-7

Date/Time End: 2006-02-02

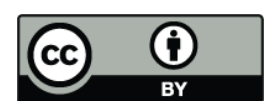

Correspondence to: T. Tanhua

(ttanhua@ifm-geomar.de)

Published by Copernicus Publications. 


\begin{tabular}{lllll}
\hline $\begin{array}{l}\text { Data Product } \\
\text { Parameter Name }\end{array}$ & $\begin{array}{l}\text { Data Product } \\
\text { Flag Name }\end{array}$ & $\begin{array}{l}\text { Exchange File } \\
\text { Parameter Name }\end{array}$ & $\begin{array}{l}\text { Exchange File } \\
\text { Flag Name }\end{array}$ & Units \\
\hline $\begin{array}{l}\text { station } \\
\text { day }\end{array}$ & & $\begin{array}{l}\text { STANBR } \\
\text { Donth }\end{array}$ & $\begin{array}{l}\text { DATE } \\
\text { DATE }\end{array}$ & \\
year & & DATE & & \\
latitude & LATITUDE & & decimal degrees \\
longitude & LONGITUDE & & decimal degrees \\
cruiseno & & & \\
depth & & meters \\
temperature & & CTDTMP & & \\
salinity & SALNTY & SALNTY_FLAG_W & \\
pressure & Sf & CTDPRS & decibars \\
nitrate & NITRAT & NITRAT_FLAG_W & micomole $\mathrm{kg}^{-1}$ \\
nitrite & no3f & NITRIT & NITRIT_FLAG_W & micomole $\mathrm{kg}^{-1}$ \\
silicate & no2f & SILCAT & SILCAT_FLAG_W & micomole $\mathrm{kg}^{-1}$ \\
phosphate & sif & PHSPHT & PHSPHT_FLAG_W & micomole $\mathrm{kg}^{-1}$ \\
\hline
\end{tabular}

For a complete list of parameters for the CARINA data base, see Key et al. (2009). Note the different names for the parameters in the Exchange files (the individual cruise files) and the merged data product.

\section{Introduction and instrumentation}

CARINA (CARbon IN the Atlantic) is a database of carbon and carbon-relevant data from hydrographic cruises in the Arctic, Atlantic and Southern Oceans. The project started as an essentially informal, unfunded project in Delmenhorst, Germany, in 1999 during the workshop on " $\mathrm{CO}_{2}$ in the North Atlantic", with the main goal to create a uniformly formatted database of carbon relevant variables in the ocean to be used for accurate assessments of oceanic carbon inventories and uptake rates. The collection of data and the quality control of the data have been a main focus of the CARINA project. Both primary and secondary quality control (QC) of the data have been performed. With the exception of three cruises that were included in GLODAP (Key et al., 2004), each CARINA dataset is appraised for primary and secondary data quality for the first time. Whilst GLODAP focused primarily on World Ocean Circulation Experiment (WOCE)/Joint Global Ocean Flux Study (JGOFS) cruises, the CARINA database concentrates on post-WOCE cruises up to and including 2005. The two databases are thus complementary to each other. The CARINA database consists of two parts: the first part is formed by the set of individual cruise files where all the data reported by the measurement teams are stored. Quality flags accompany the data, in many cases they are the flags originally reported, in others they are assigned by R. Key. These files are in WHP (WOCE Hydrographic Program) exchange format where the first lines consist of the condensed metadata. There are essentially no calculated or interpolated values in the individual cruise files, with the exceptions of pressure calculated from depth and some bottle salinities that were taken from ctdsal. No adjustments have been applied to any of these values with the exception that all $\mathrm{pH}$ measurements were converted to the seawater $\mathrm{pH}$ scale at $25^{\circ} \mathrm{C}$.
The second part of CARINA consists of three merged quality controlled and adjusted data files; one each for the Atlantic Ocean, Arctic Mediterranean Seas and Southern Ocean regions. These files contain all the CARINA data and also include: 1) interpolated values for nutrients, oxygen and salinity if those are missing and the interpolation could be made according to certain criteria, as described in Key et al. (2009); and 2) calculated carbon parameters; e.g. if Total Carbon Dioxide $\left(\mathrm{TCO}_{2}\right)$ and Total Alkalinity (TA) were measured, $\mathrm{pH}$ was calculated. Calculated and interpolated values have been given the quality flag " 0 ", with all the values in the merged data file having been adjusted according to the adjustment described in Sect. 4. In many cases there are additional parameters in the individual cruise files which have not been included in the secondary $\mathrm{QC}$, such as $\Delta^{14} \mathrm{C}, \delta^{13} \mathrm{C}$ and $\mathrm{SF}_{6}$. These are included in the merged data files as well.

This report provides an overview of the nutrient data in CARINA-ATL, and describes the secondary QC of nutrient data for this data set. An overview of the Atlantic Ocean part of the CARINA data set (CARINA-ATL) data set is given in Tanhua et al. (2009a), and a more comprehensive description of the complete CARINA database can be found in Key et al. (2009).

\section{Data provenance}

The CARINA database includes data and metadata from 188 oceanographic cruises/campaigns, of which five entries consist of multiple cruises. The Atlantic Ocean subset of the CARINA data set consists of 98 cruises/entries, of which one is a time series and a further two are collections of multiple cruises conducted over several years within the framework of a common project. Additionally, six reference cruises were included in the secondary QC for CARINA-ATL to ensure 
Table 1. All CARINA cruises in the Atlantic Ocean region were at least one nutrient was measured. The reference cruises are included in this table even though they are not part of CARINA; ND: no data (i.e. not measured), NC: not considered (i.e. did for some reason not go through secondary QC), poor: data not included in the data product. Note that data labeled NC are included in the data product.

\begin{tabular}{|c|c|c|c|c|c|c|c|c|}
\hline No & EXPOCODE & Core & Ref & $\mathrm{NO}_{3}$ & $\mathrm{PO}_{4}$ & $\mathrm{SiO}_{3}$ & nutrient analyst/institute & Chief Scientist \\
\hline 7 & 06GA20000506 & 1 & 0 & 1 & 1 & 1.06 & H. Johannesen & P. Kolterman \\
\hline 8 & 06МТ19920316 & 0 & 0 & $\mathrm{NC}$ & $\mathrm{NC}$ & $\mathrm{NC}$ & ND & O. Pfannkuche \\
\hline 9 & 06МТ19920509 & 0 & 0 & 1 & 0.90 & 1 & T. Korner & J. Duinker \\
\hline 12 & 06МT19941012 & 0 & 0 & 1 & 1 & 1 & IFM Kiel & P. Kolterman, J. Meincke \\
\hline 13 & 06MT19941115 & 1 & 0 & 0.98 & 1 & 1 & J. Duinker, L. Mintrop & J. Meincke \\
\hline 14 & 06МT19960613 & 0 & 0 & 1 & 1.15 & 1.11 & L. Mintrop & K. Kremling \\
\hline 15 & 06МT19960910 & 0 & 0 & 1 & 1 & 1.05 & Lendt & C. Hemleben \\
\hline 16 & 06МT19970107 & 0 & 0 & 1 & 1.05 & 1.13 & O. Llinas & T. Müller \\
\hline 17 & 06MT19970515 & 1 & 0 & 1.05 & 0.95 & 1 & IFM Kiel & W. Zenk, T. Müller \\
\hline 18 & 06MT19970707 & 1 & 0 & 1.02 & ND & 1 & IFM Kiel & F. Schott \\
\hline 19 & 06МT19970815 & 1 & 0 & 1 & 1 & 1 & BSH & A. Sy \\
\hline 20 & 06МT19990610 & 0 & 0 & 1 & 1 & 1 & IFM Kiel & W. Zenk \\
\hline 21 & 06МT19990711 & 0 & 0 & 1 & 1.04 & 1 & IFM Kiel & F. Schott \\
\hline 23 & 06МT20010507 & 0 & 0 & 1 & 1.11 & 1 & IFM Kiel & J. Fischer \\
\hline 25 & 06МT20010717 & 0 & 0 & 1 & 1.25 & 1 & IFM Kiel & W. Zenk \\
\hline 28 & 06МT20021013 & 0 & 0 & 1 & 1 & 0.92 & F. Malien & D. Wallace \\
\hline 30 & 06МT20030723 & 1 & 0 & 1 & 1 & 1 & F. Malien & M. Rhein \\
\hline 32 & 06МT20040311 & 1 & 0 & 1 & 0.97 & 1 & F. Malien & D. Wallace \\
\hline 37 & 18HU19920527 & 0 & 0 & 1 & 0.98 & 1 & ND & J. Lazier \\
\hline 38 & 18HU19930405 & 0 & 0 & $\mathrm{NC}$ & $\mathrm{NC}$ & $\mathrm{NC}$ & ND & N. Oakey \\
\hline 39 & 18HU19930617 & 1 & 0 & 1 & 1 & 1 & ND & J. Lazier \\
\hline 40 & 18HU19931105 & 0 & 0 & 1 & 1 & 1 & ND & A. Clarke \\
\hline 41 & 18HU19940524 & 0 & 0 & 1 & 0.89 & 1 & ND & J. Lazier \\
\hline 42 & 18HU19941012 & 0 & 0 & 1 & 1 & 1 & ND & A. Clarke \\
\hline 43 & 18HU19950419 & 0 & 0 & 1 & 1 & 1 & P. Clement & A. Clarke \\
\hline 44 & 18HU19970509 & 1 & 0 & 1 & 1 & 1 & P. Strain, J. Lazier & A. Clarke \\
\hline 51 & 29CS19771007 & 0 & 0 & $\mathrm{NC}$ & $\mathrm{NC}$ & $\mathrm{NC}$ & ND & F. Fraga \\
\hline 52 & $29 \mathrm{CS} 19930510$ & 0 & 0 & 1.03 & 1 & $\mathrm{NC}$ & A. Alvarez, G. Roson & J. M. Cabanas \\
\hline 53 & 29GD19821110 & 0 & 0 & 1.02 & 0.98 & ND & ND & F. Fraga \\
\hline 54 & 29GD19831201 & 0 & 0 & $\mathrm{NC}$ & $\mathrm{NC}$ & $\mathrm{NC}$ & ND & F Fraga \\
\hline 55 & 29GD19840218 & 0 & 0 & 0.95 & 1 & 1 & ND & F. Fraga \\
\hline 56 & 29GD19840711 & 0 & 0 & 1 & 1 & 1 & ND & F. Fraga \\
\hline 57 & 29GD19860904 & 0 & 0 & 1 & 1 & 1 & ND & F. Fraga \\
\hline 60 & 29HE19980730 & 0 & 0 & 1.07 & poor & 1.14 & E. \& D. de Armas & F. Perez \\
\hline 61 & 29HE20010305 & 0 & 0 & 1 & 1 & 1 & C. Castro & A. Rios \\
\hline 62 & 29HE20020304 & 1 & 0 & 1 & 1 & 1 & C. Castro & F. Perez \\
\hline 63 & 29HE20030408 & 0 & 0 & 1 & 1.12 & 1.08 & C. Castro & A. Rios \\
\hline 64 & $31 \mathrm{AN} 19890420$ & 0 & 0 & 1 & 1 & 1 & ND & P. Brewer \\
\hline 68 & 316 N20030922 & 1 & 0 & 1 & 1 & 1 & S. Becker/E. Quiroz & J. Toole/A. MacDonald \\
\hline 69 & $316 \mathrm{~N} 20031023$ & 1 & 0 & 1 & 1.03 & 1 & S. Becker/D. Schuller & T. M. Joyce/W. M. Smethie \\
\hline 71 & 32EV19910328 & 0 & 0 & 1.05 & 1 & 1 & ND & R. Pickart \\
\hline 84 & 33LK19960415 & 0 & 0 & 1 & 1 & 1 & C. Oudot & Y. Gouriou \\
\hline 85 & 33RO19980123 & 1 & 0 & 1 & 1 & 1 & C. Mordy & K. Lee/D. Bitterman \\
\hline 86 & 33RO20030604 & 1 & 0 & 1 & 1 & 1 & C. Mordy/G. Johnson & J. Bullister/N. Gruber \\
\hline 87 & 33RO20050111 & 1 & 0 & 1 & 1.03 & 1 & AOML/U. Miami & R. Wanninkhof/S. Doney \\
\hline 88 & 33 SW20010102 & 0 & 0 & $\mathrm{NC}$ & $\mathrm{NC}$ & $\mathrm{NC}$ & ND & A. Michaels/D. Capone \\
\hline 89 & 33 SW20010102 & 0 & 0 & $\mathrm{NC}$ & $\mathrm{NC}$ & $\mathrm{NC}$ & ND & A. Michaels/D. Capone \\
\hline
\end{tabular}

consistency between CARINA and historical databases, in particular GLODAP (Global Ocean Data Analysis Project, Key et al., 2004). Five of the Atlantic cruises are in common with the Southern Ocean region, and five are in common with the Arctic Mediterranean Seas region. These overlapping cruises ensure consistency between the three regions of the CARINA data set. The Atlantic Ocean region of CARINA is loosely defined as the area between of the Greenland-Scotland Ridge and $30^{\circ} \mathrm{S}$, but as mentioned, ten cruises overlap with the surrounding regions, thus extending the area covered. For the CARINA-ATL data set, a subset of cruises was identified as core cruises, see Table 1. These were chosen based both on the geographical extent of the data set (i.e. cruises that cover only a small and limited area could not become a core cruise) and an expected high quality of data (i.e. cruises with expected WOCE/CLIVAR quality). Any offsets towards these core cruises were weighed higher in the secondary QC. Note that even though all reference cruises were also selected as core cruises; several nonreference cruises were selected as core cruises.

The cruises included in the CARINA data products generally exclude those that were included in GLODAP. This was done primarily to facilitate later merging of these two data products. There are, 
Table 1. Continued.

\begin{tabular}{|c|c|c|c|c|c|c|c|c|}
\hline No & EXPOCODE & Core & Ref & $\mathrm{NO}_{3}$ & $\mathrm{PO}_{4}$ & $\mathrm{SiO}_{3}$ & nutrient analyst/institute & Chief Scientist \\
\hline 91 & 34AR19970805 & 0 & 0 & 1.05 & 1.04 & 1.15 & T. Tanhua & H. Gronvall/J. Launiainen \\
\hline 92 & $35 \mathrm{~A} 320010203$ & 0 & 0 & 0.98 & 1 & ND & ND & L. Prieur \\
\hline 93 & $35 \mathrm{~A} 320010322$ & 0 & 0 & 0.98 & 1 & ND & ND & M. Bianchi \\
\hline 94 & 35LU19890509 & 0 & 0 & 1 & 1 & 1 & F. Fraga & ND \\
\hline 95 & 35LU19950909 & 0 & 0 & 1 & 1 & 1 & P. Fournier/C. Oudot & Y. Gouriou \\
\hline 106 & 35TH19990712 & 0 & 0 & 1 & poor & 1 & Y. Gouriou & Y. Gouriou \\
\hline 107 & $35 \mathrm{TH} 20010823$ & 0 & 0 & 1 & 0.96 & 1.07 & ND & J.-C. Gascard \\
\hline 108 & $35 \mathrm{TH} 20020611$ & 1 & 0 & 1 & 0.96 & 1 & P. Morin & H. Mercier \\
\hline 109 & $35 \mathrm{TH} 20040604$ & 1 & 0 & 0.96 & 1.10 & 0.98 & P. Morin & T. Huck \\
\hline 113 & 49NZ20031106 & 1 & 0 & 1 & 1 & 1 & M. Aoyama & Y. Yoshikawa \\
\hline 130 & 58JH19920712 & 0 & 0 & $\mathrm{NC}$ & $\mathrm{NC}$ & $\mathrm{NC}$ & F. Rey & J. Blindheim \\
\hline 135 & 58JH19940723 & 0 & 0 & $\mathrm{NC}$ & poor & $\mathrm{NC}$ & F. Rey & J. Blindheim \\
\hline 151 & 64PE19960618 & 0 & 0 & 1 & 1 & 1 & van Aken, van Weerlee, van Ooijen/P. Berkhout, M. Manuels & H. M. van Aken \\
\hline 152 & 64PE20000926 & 0 & 0 & 1 & 0.96 & 1 & H. M. van Aken & H. M. van Aken \\
\hline 153 & 64TR19890731 & 0 & 0 & 0.96 & poor & 1 & ND & ND \\
\hline 154 & 64TR19900417 & 0 & 0 & 1 & 0.96 & 1 & I. Flameling, R. deVries, K. Bakker & H. G. Fransz \\
\hline 155 & 64TR19900701 & 1 & 0 & 1 & 1 & 1 & H. M. van Aken & H. M. van Aken \\
\hline 156 & 64TR19900714 & 0 & 0 & 1 & 1 & 1 & H. M. van Aken & H. M. van Aken \\
\hline 157 & 64TR19910408 & 1 & 0 & 1 & 0.93 & 1 & H. M. van Aken & H. M. van Aken \\
\hline 158 & 67SL19881117 & 0 & 0 & $\mathrm{NC}$ & ND & $\mathrm{NC}$ & ND & A. Rios \\
\hline 159 & 74AB19900528 & 0 & 0 & 1.11 & 1 & $\mathrm{NC}$ & ND & ND \\
\hline 160 & $74 \mathrm{AB} 19910501$ & 0 & 0 & 1 & 1 & 0.97 & S. Hartman/R. Paylor & R. Pollard \\
\hline 161 & 74AB19910614 & 0 & 0 & $\mathrm{NC}$ & $\mathrm{NC}$ & $\mathrm{NC}$ & ND & ND \\
\hline 162 & 74AB19910712 & 0 & 0 & $\mathrm{NC}$ & ND & 0.9 & ND & ND \\
\hline 164 & 74AB20050501 & 0 & 0 & 0.98 & 0.97 & 0.93 & R. Sanders & E. McDonagh \\
\hline 165 & 74DI19890511 & 0 & 0 & $\mathrm{NC}$ & ND & ND & ND & ND \\
\hline 166 & 74DI19890612 & 0 & 0 & poor & ND & poor & ND & ND \\
\hline 167 & 74DI19890716 & 0 & 0 & poor & poor & 1 & ND & ND \\
\hline 168 & 74DI19900425 & 0 & 0 & $\mathrm{NC}$ & $\mathrm{NC}$ & $\mathrm{NC}$ & ND & ND \\
\hline 169 & 74DI19900515 & 0 & 0 & $\mathrm{NC}$ & $\mathrm{NC}$ & $\mathrm{NC}$ & ND & ND \\
\hline 170 & 74DI19900612 & 0 & 0 & 0.95 & 1.10 & poor & ND & ND \\
\hline 171 & 74DI19970807 & 1 & 0 & 1 & 0.97 & 1 & S. Holley & S. Bacon \\
\hline 172 & 74DI19980423 & 1 & 0 & 1 & 1 & 1 & ND & D. Smythe-Wright \\
\hline 173 & 74DI20040404 & 1 & 0 & 0.97 & 1 & 0.98 & R. Sanders & S. Cunningham \\
\hline 185 & IrmingerSea & 0 & 0 & $\mathrm{NC}$ & $\mathrm{NC}$ & $\mathrm{NC}$ & J. Olafson & Various \\
\hline 187 & OMEX1NA & 0 & 0 & 1 & 1 & 1 & Various & Various \\
\hline 188 & OMEX2 & 0 & 0 & 1 & 1 & $\mathrm{NC}$ & Various & Various \\
\hline ND & 29HE19920714 & 1 & 1 & 1 & poor & 0.97 & A. Cruzado & G. Parrilla \\
\hline ND & 316 N19961102 & 1 & 1 & 1 & 0.96 & 1 & ND & K. Johnson \\
\hline ND & $316 \mathrm{~N} 19970717$ & 1 & 1 & 1 & ND & 1 & J. Jennings/B. Sullivan & B. Pickart \\
\hline ND & 316 N19970815 & 1 & 1 & 1 & 1 & 1 & A. A. Ross/J. Arrington & T. M. Joyce \\
\hline ND & 317519930704 & 1 & 1 & 1 & 1 & 1.03 & ND & R. Wanninkhof \\
\hline ND & 323019940104 & 1 & 1 & 1 & 1 & 1 & X. Alvarez-Salgado/C. G. Castro & L. Mémery \\
\hline
\end{tabular}

however, 3 exceptions: 06MT19941012, 06MT19941115 and 74DI19970807 (Cruise Numbers 12, 13 and 171 respectively). These cruises were added to CARINA because additional parameters critical to the CARINA goals became available after GLODAP was published. The CARINA 2nd QC, however, made full use of many of the GLODAP cruises and details are given in many of the accompanying papers in this issue. The adjustments for nutrients data in the GLODAP data set (Gouretski and Jancke, 2001) differ in a number of ways from those applied in CARINA. Adjustments in GLODAP are: (i) additive as opposed to multiplicative, (ii) are objectively applied based on inversion results, as compared to the somewhat "subjective" component of CARINA (Tanhua et al., 2009b); and (iii) are based on comparisons with a completely different set of cruises. The nutrient adjustments suggested to nine GLODAP cruises suggested by CARINA are included in this report; six of these are not formally part of the CARINA data set (Table 3 in Tanhua et al., 2009b). Figure 1 shows the position of all stations where at least one nutrient was measured (i.e. phosphate, silicate or nitrate) in the CARINA data base, and the cruises are all listed in Table 1 together with the adjustments that have been applied for the nutrient data in the data product.

The nutrient data are reported in units of $\mu \mathrm{mol} \mathrm{kg}^{-1}$. However, there is one complication with nitrate data. In ideal cases nitrate and nitrite measurements were reported separately. In others only nitrate was reported or only the combination of nitrate plus nitrite. Finally, in a few instances nitrate plus nitrite was reported along with values for nitrite. For the last example the nitrite values were simply subtracted from the reported nitrate plus nitrite values. For cases where only nitrate plus nitrite was reported we had a choice: carry an additional parameter (i.e. $\mathrm{NO}_{3}+\mathrm{NO}_{2}$ in addition to nitrate) or simply rename the data nitrate (ignoring the nitrite 


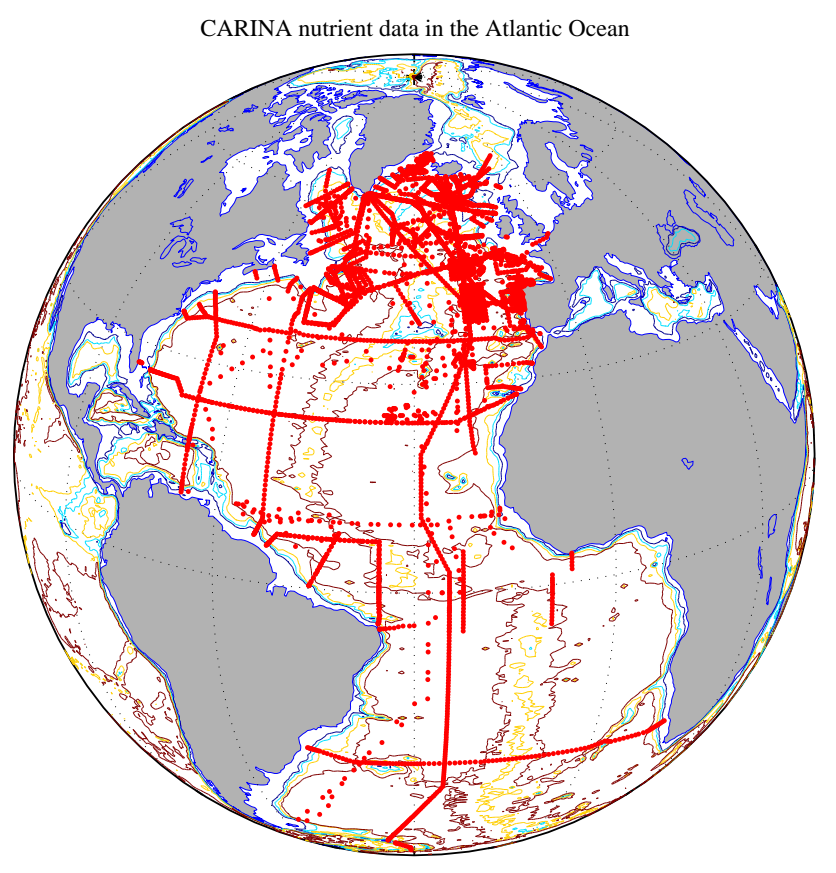

Figure 1. Map of the positions of all stations with at least one nutrient measurement (i.e. nitrate, phosphate or silicate) in the CARINA data base for the Atlantic Ocean.

contribution in the upper water column). Both choices are problematic. We chose the latter for CARINA cruises (both original cruise files and final data products). We encourage investigators to report nitrate and nitrite values separately in the future to avoid this problem. Another source of error that we were not able to completely eliminate is the possibility of erroneous units for the nutrients, i.e. that data were given in volumetric units instead of the stated gravimetric units, or vice-versa. Both cases would cause an offset of 2-3\%.

\section{Methods}

The quality control of the CARINA-ATL nutrient data followed the procedures described in Tanhua et al. (2009b). The single most important strategy in the secondary quality control of nutrients was the crossover analysis, i.e. cruise tracks that crossed each other, or at least came close to each other, were considered as a crossover. For each crossover, comparisons of the nutrient concentrations were made on sigma-4 density surfaces in the deep part of the water column (i.e. $>1500 \mathrm{~m}$ depth) the result of which being an offset and a standard deviation of the offset. These were pooled with offsets and uncertainties from all other crossovers and used to generate a set of corrections for each cruise using a set of least square inversions, suggestions that were then critically examined in light of local variability and crossover with core cruises. After the crossover analysis, and armed with the corrections suggested by the inversion, the offsets for each vari- able (nitrate, phosphate and silicate) and each cruise were scrutinized, and an adjustment was applied to the data product. For nutrients multiplicative adjustments were used, and all were agreed on within the CARINA-ATL group during a meeting in Paris in June of 2008. No adjustments smaller than $2 \%$ were made to the nutrients based on the typically reported values of precision of nutrient measurements and the expected natural variability of nutrient concentrations in the deep water of the Atlantic Ocean. Based on an error analysis of the crossover analysis, Tanhua et al. (2009b) reports on the RMSE of the differences between offsets calculated with two slightly different crossover methods. They found that the RMSE is large for silicate $(7 \%)$ and phosphate $(4.2 \%)$ but slightly smaller for nitrate $(2.9 \%)$. Tanhua et al. (2009b) suggests that adjustments smaller than the RMSE between the two methods might be too optimistic, i.e. that analytical precision and/or natural variability prevents unambiguous adjustments to be made. It thus seems that the $2 \%$ cut-off limit was somewhat optimistic for phosphate and silicate, but realistic for nitrate.

Three sources of evidence were used for the determination of adjustments for the nutrient values: the corrections suggested by the inversion, the average of the offsets for all crossovers, and the crossover results to the core cruises. Any offsets toward these core cruises did generally weigh higher in the secondary QC with the exception of a few core cruises that needed adjustment of nutrient values themselves. Plots of nitrate vs. phosphate were an additional useful tool to identify cruises where a bias in one of the two nutrients (phosphate or nitrate) could be identified (Fig. 2). A N:P ratio very different from 16 (Redfield et al., 1963), or with an intercept very different from 0 was taken as an indication of a bias in one, or both, of the two nutrient measurements. A second inversion was made using the adjusted CARINA-ATL data, and all remaining corrections larger than $\pm 2 \%$ were evaluated again. This process led to a small number of changes to the adjustments agreed on in Paris.

Nutrient values in the deep water of the Atlantic Ocean are influenced by hydrographic variability. Variations in the contributions of water masses originating in the south or the north are of great importance, the southern end member particularly having higher concentrations of silicate. The Mediterranean outflow also has different nutrient concentrations compared to the Atlantic water in the same density range. Water samples in areas prone to variations in Antarctic Bottom Water and/or Mediterranean Water are therefore somewhat more difficult to apply adjustments to. This was taken into consideration during the secondary QC process and larger offsets were generally tolerated before an adjustment was applied in areas affected by this variability (e.g. Tanhua et al., 2009a). 


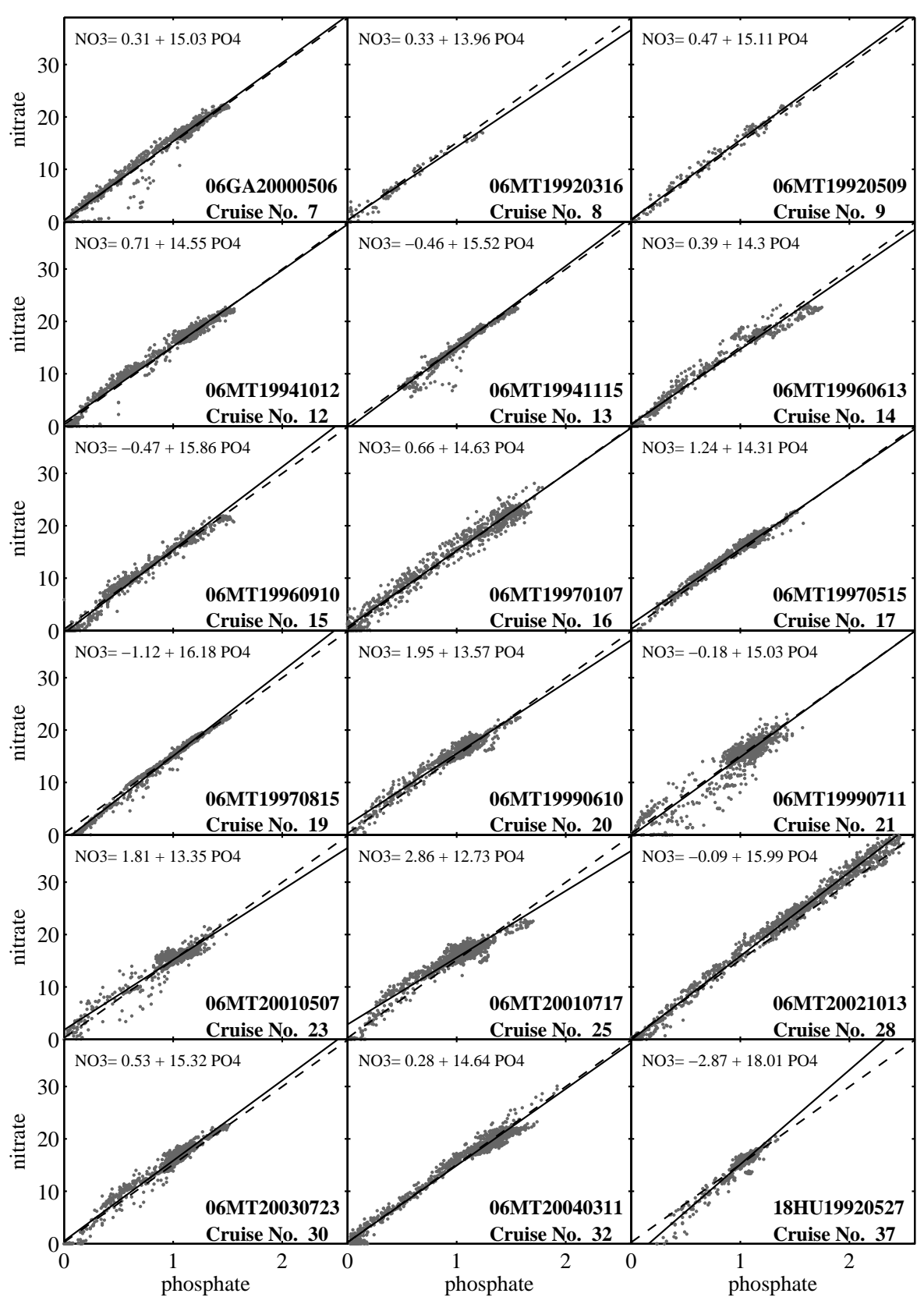

Figure 2. Panels with the concentrations of nitrate vs. phosphate for the CARINA-ATL cruises. The linear regression (solid line) to the data are displayed in the top left corner of each panel. The dashed line is the linear fit to all the CARINA-ATL nutrient data (nitrate $=0.277+14.85 \times$ phosphate $)$.

\section{Atlantic Ocean nutrient analysis}

The analysis of the CARINA data make it abundantly clear that there is an urgent need to adopt practices of using certified reference materials (CRMs) for nutrients. Also for GLODAP, Key et al. (2004) noted the need for nutrient standards similar to the carbon CRMs. Progress has been made (Aoyama et al., 2008; Aminot and Kirkwood, 1995), but so far, the use of nutrient "CRMs" has not been gen- erally adopted. The community must adopt a set of CRMs and those "standards" should be used on every cruise. This change in methodology is absolutely critical if we are ever to understand subtle changes in nutrient distributions and stoichiometric ratios in a changing ocean environment.

In general, the nitrate data showed the largest consistency between cruises, whereas phosphate data varied considerably more, likely due to analytical difficulties. Silicate data also showed large offsets between cruises, but in this case it 


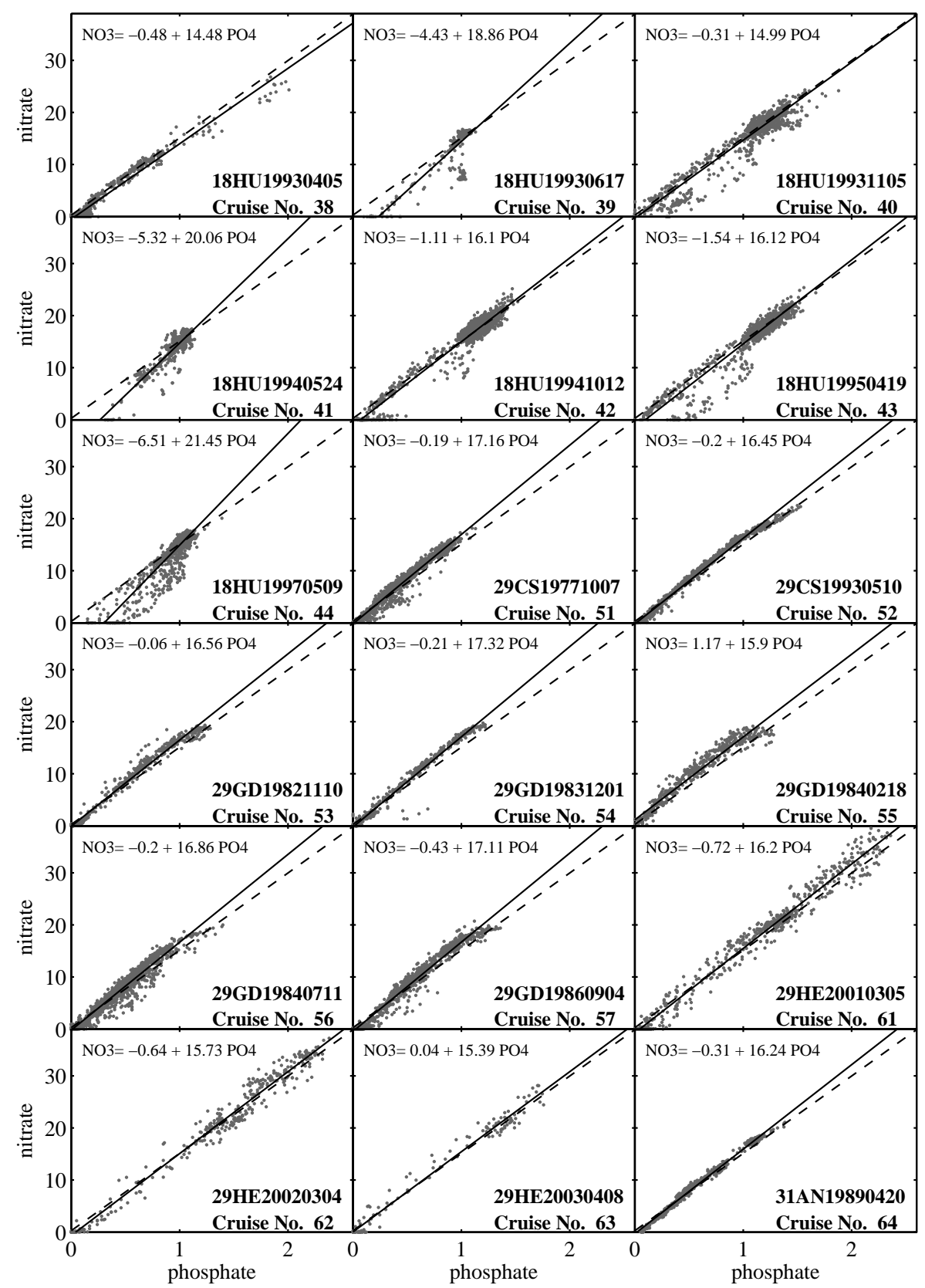

Figure 2. Continued.

seemed to be due to natural variability in addition to analytical biasing, i.e. varying fractions of Antarctic Bottom Water with high silicate concentrations. Thus, secondary QC was more difficult to perform for silicate than for the other nutrients, and a somewhat larger tolerance to natural variability was allowed. The offsets for the crossovers calculated for the data product were used to estimate the overall accuracy of the nutrient data, Fig. 3. We calculated the weighted mean (WM) for each of the three nutrients using the absolute value of the offset $(D)$ of $L$ crossovers with the uncertainty $(\sigma)$ :
$\mathrm{WM}=\frac{\sum_{i=1}^{L} D(i) /\left(\sigma(i)^{2}\right.}{\sum_{i=1}^{L} 1 /\left(\sigma(i)^{2}\right.}$

Based on this analysis we estimate the internal consistency of the CARINA-ATL nutrient data to: nitrate 1.5\%; phosphate 2.6\%; silicate $3.1 \%$. The corrections to the CARINA-ATL nutrient data suggested by the inversion are shown in Fig. 4. All results and analyses made by the authors for the secondary QC, including figures for each individual crossover 


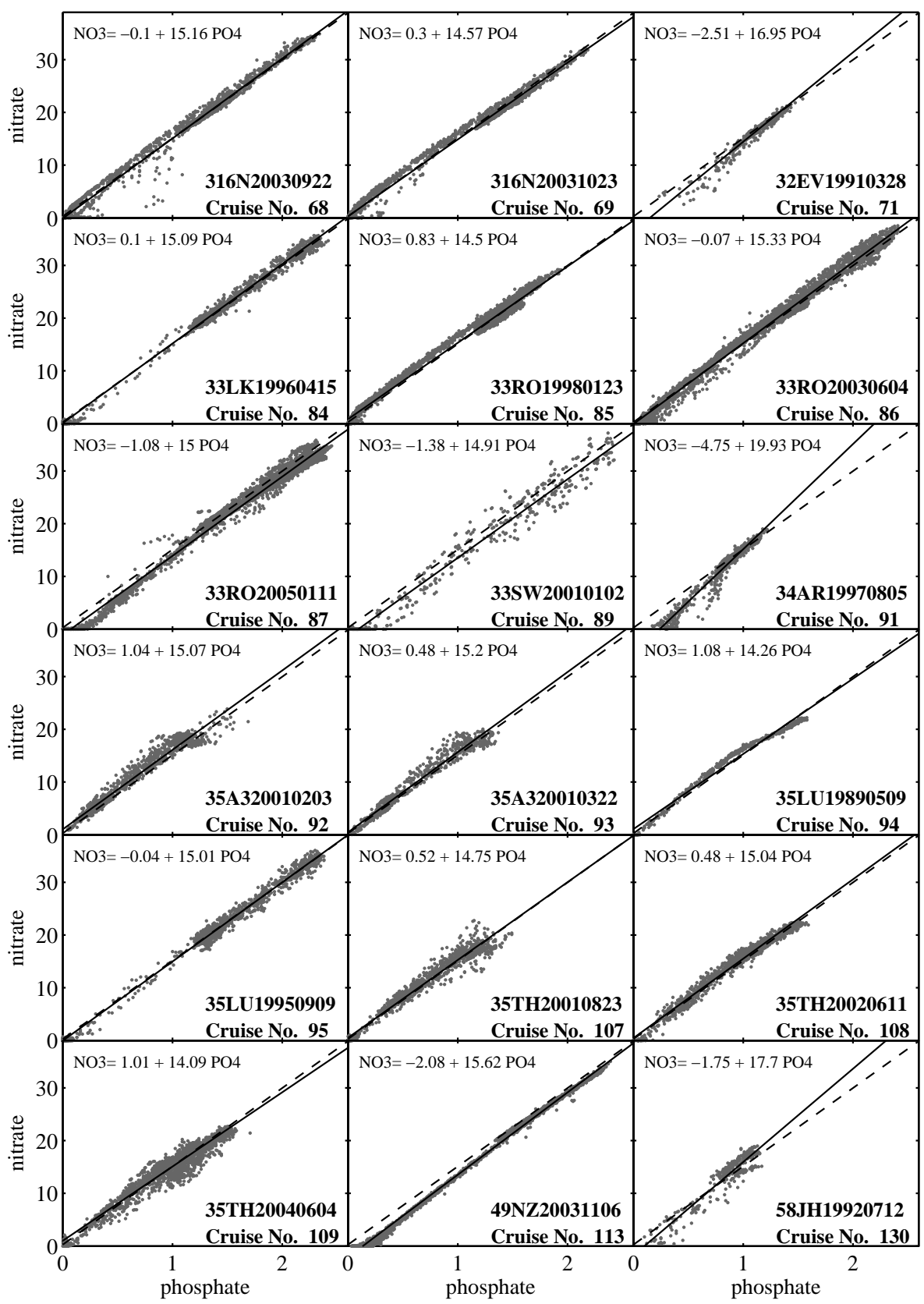

Figure 2. Continued.

can be found on the CARINA website (Tanhua et al., 2009b) at http://cdiac.ornl.gov/oceans/CARINA/Carina_inv.html.

In Sect. 4.1 we show the motivation for all adjustments that have been applied to the nutrient data. In some cases the lack of an adjustment for a cruise that has large offsets to other cruises is also explained here. Nutrient data that did not show any evidence of bias are not further discussed.

A crossover results in an offset for the cruise of interest (cruise A) relative to another cruise (cruise B), i.e. offset $=$ cruise A/cruise $B$. Thus if the offset is less than unity, the values from cruise A are lower than those from cruise B. Similarly, if the average of all crossovers for cruise A is less than unity, the values from cruise A are lower than the values from other cruises in the area. The inversion process results in a suggestion for a correction to cruise A. If cruise $\mathrm{A}$ is lower than other cruises in the area, the correction will most likely be larger than unity, i.e. the data from cruise A will have to be corrected upwards for consistency with other cruises. When we discuss adjustment, we refer to the correction that was actually applied to the data. 

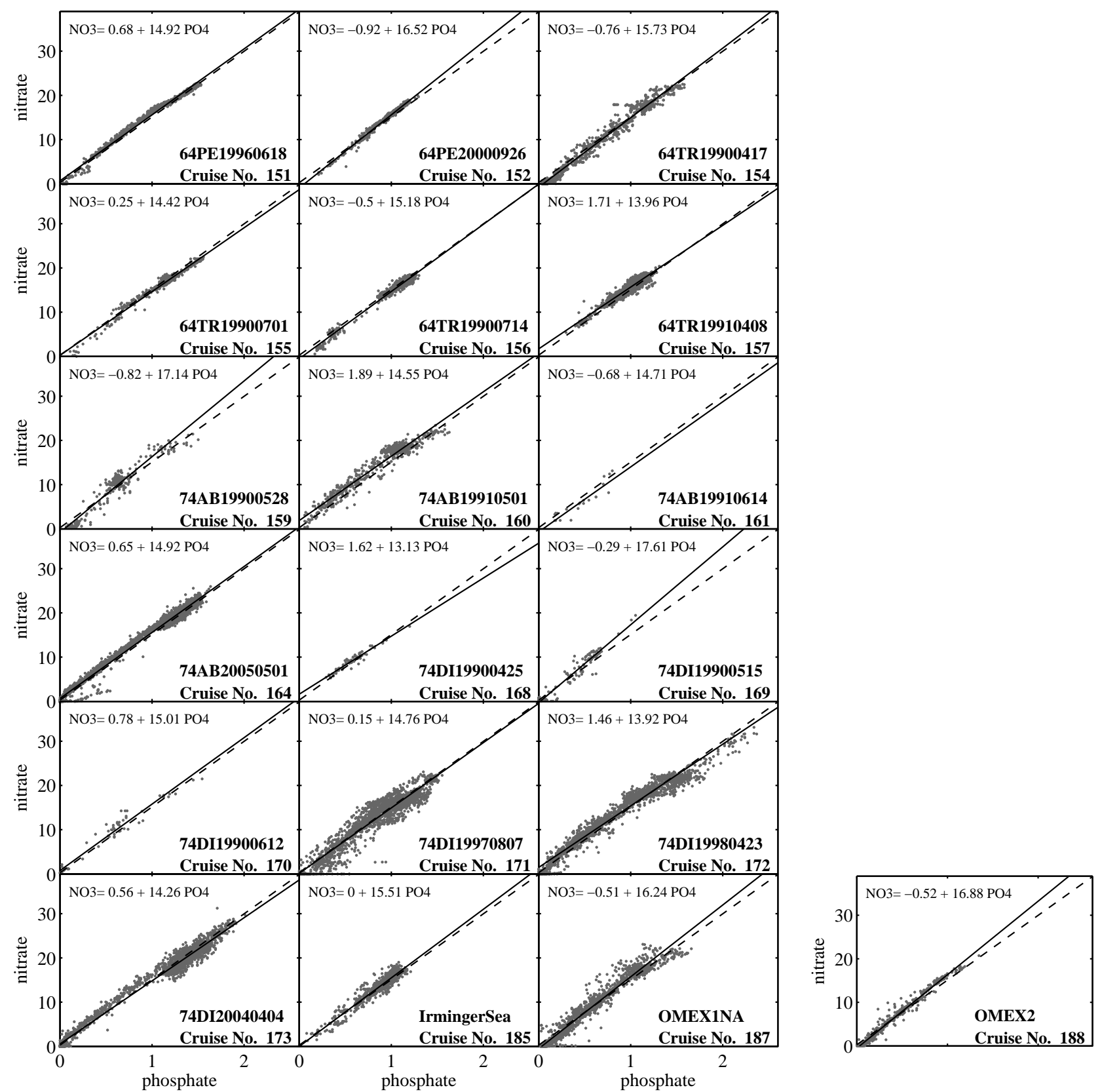

Figure 2. Continued.

Consider for example the silicate data from cruise 06GA20000506 (below): the silicate data seems to be low compared to other cruises in the area since the average offset of all crossovers is less than unity (0.94). Thus 06GA20000506 would need a correction that is larger than unity to be consistent with the other cruise, exactly what the inversion then suggests (1.05-1.06). Based on this evidence, we applied an adjustment of 1.05 to the silicate data for this cruise, i.e. the reported silicate data were multiplied with 1.05 in the data product. While the secondary QC suggested objectively determined quantitative corrections, the applied adjustments were subjectively determined by the CARINAATL working group based on all available evidence and firsthand information regarding methods, personnel etc.

Each cruise in the collection was assigned an EXPOCODE (Swift, 2008). These codes provide an unique identifier and are composed of a NODC (National Ocean Data Center) platform code for the research vessel (http://www.nodc. noaa.gov/General/NODC-Archive/platformlist.txt) followed by the date when the cruise left port. The NODC code 

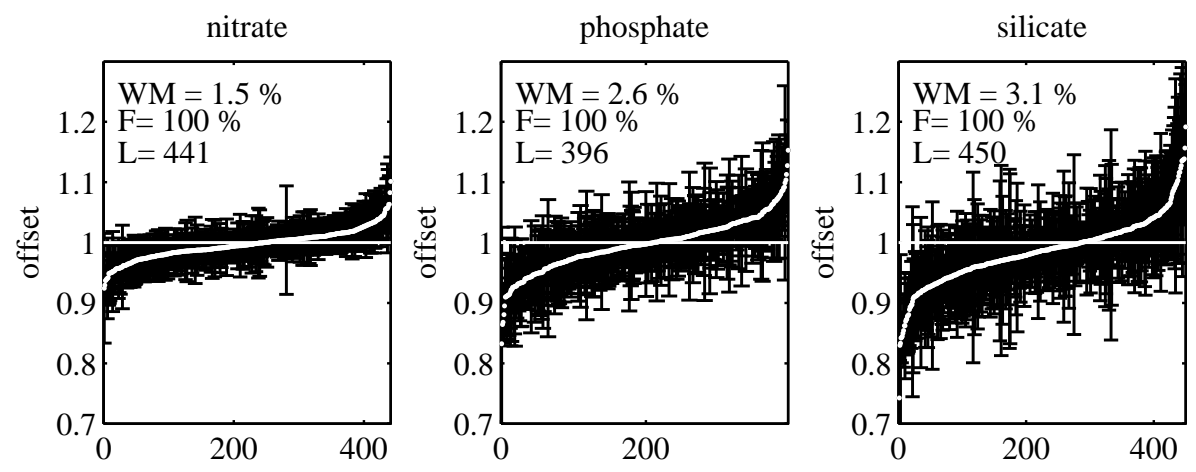

Figure 3. Offsets calculated for the crossovers in the CARINA-ATL data after adjustments have been applied. WM: the weighted mean of the offsets (see text); F: the percentage of offsets indistinguishable from 1 within their uncertainty; L: the number of crossovers.

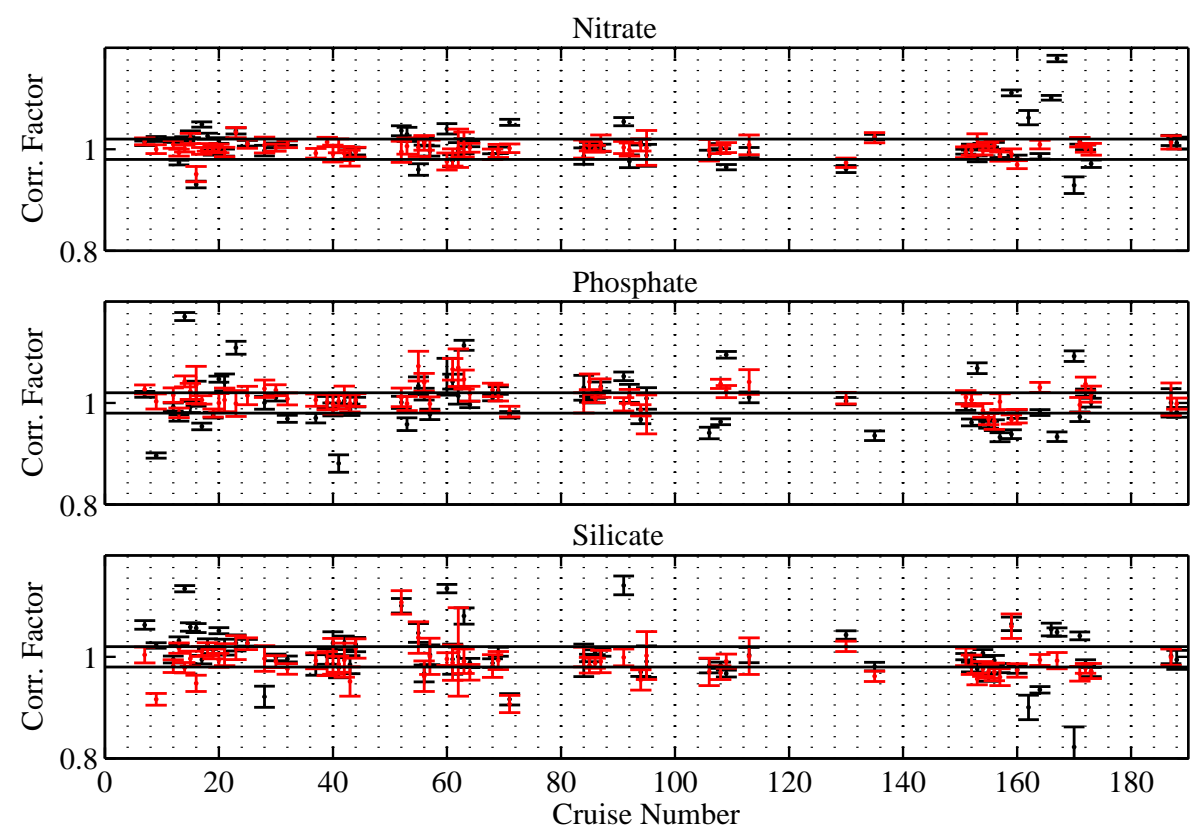

Figure 4. Correction factors for the CARINA-ATL nutrient data suggested by the WDLSQ inversion. Black markings denote the correction factors of the original data, and the red markings denote the corrections determined from the inversion made on the adjusted dataset. The horizontal black lines denote the $\pm 2 \%$ adjustment, the lower limit for any adjustments.

is composed of a 2 digit country code and a 2 character (number or letter) ship code. For instance, EXPOCODE 06MT20040311 refers to a cruise conducted on the German (06) ship Meteor (MT) and that the cruise departed on 11 March 2004. In a few instance "cruises" were not single cruises, but cruise collections representing a single investigator or a single project. Assignment of an EXPOCODE in these cases was inappropriate so they were simply named.

\subsection{Nutrient adjustments}

\section{GA20000506, cruise \#7}

Silicate: The average of all crossovers is 0.94 and the inversion suggest a correction of 1.05-1.06. Crossovers with the core cruises suggest that the silicate data are too low. Based on this evidence, an adjustment of 1.06 was applied to the silicate data. 
06MT19920316, cruise \#8

This cruise has only 1 deep station with nutrient samples, which prevent crossover analysis, and make the secondary QC difficult. The nutrient data for this cruise are not considered in the secondary QC.

\section{MT19920509, cruise \#9}

Nitrate: The average of all crossovers is 1.10 and the inversion suggests a correction of 0.9 . Crossovers with the core cruises suggest that the nitrate data are too high. Based on this evidence, an adjustment of 0.90 was applied to the nitrate data.

\section{MT19941012, cruise \#12}

Nutrients for this cruise were analyzed by Gouretski and Jancke (2001) who determined biases for nitrate, phosphate and silicate of $-0.07,0.04$ and $-1.8 \mu \mathrm{mol} / \mathrm{kg}$ respectively. The inversion suggests only minor corrections to the nutrient data, agreeing with the corrections by Gouretski and Jancke (2001). The CARINA group did not apply any adjustments to the nutrient data for this cruise.

\section{MT19941115, cruise \#13}

Nutrients for this cruise were analyzed by Gouretski and Jancke (2001) who determined biases for nitrate, phosphate and silicate of $0.79,0.061$ and $-0.7 \mu \mathrm{mol} / \mathrm{kg}$ respectively.

Nitrate: The average of all crossovers is 1.047 and the inversion suggests a correction of 0.98 . Crossovers with the core cruises (with the exception of 18HU19970509) suggest that the nitrate data are too high. Based on this evidence, an adjustment of 0.98 was applied to the nitrate data.

\section{MT19960613, cruise \#14}

Phosphate: The average of all crossovers is 0.89 and the inversion suggests a correction of 1.17. Crossovers with the core cruises suggest that the phosphate data are too low. Based on this evidence, an adjustment of 1.15 was applied to the phosphate data.

Silicate: The average of all crossovers is 0.87 and the inversion suggests a correction of 1.13 . The crossovers with the core cruises suggest that the silicate data are too low. The crossover analysis of the adjusted data (1.13) suggests that this adjustment was too large; the new inversion suggest a correction of 0.96 , and the average of all crossovers is 1.02 . Based on this evidence, an adjustment of 1.11 was applied to the silicate data.
06MT19960910, cruise \#15

Silicate: The average of all crossovers is 0.95 (with large scatter) and the inversion suggests a correction of 1.05. The crossovers with the core cruises suggest that the silicate data are too low. Based on this evidence, an adjustment of 1.05 was applied to the silicate data.

\section{MT19970107, cruise \#16}

This cruise covers only a very small region close to the $\mathrm{Ca}$ nary Islands and has few crossovers.

Nitrate: The average of all crossovers is 1.01 and the inversion suggests a correction of 0.95 . Crossovers with the two repeats of the A05 section suggest that the nitrate data are good. Based on this no adjustment was applied to the nitrate data.

Phosphate: The average of all crossovers is 1.06 (heavily biased by one outlier) and the inversions suggest a correction of 1.02. The crossovers with the two repeats of the A05 section suggest that the phosphate data are too low. Based on this evidence, an adjustment of 1.05 was applied to the phosphate data.

Silicate: The average of all crossovers is 0.86 and the inversion suggests correction of 1.07. Crossovers with the two repeats of the A05 section and 33RO19980123 suggest that the silicate data are too low. Based on this evidence, an adjustment of 1.13 was applied to the silicate data.

\section{MT19970515, cruise \#17}

Nitrate: The average of all crossovers is 0.96 and the inversion suggest a correction of 1.04-1.05. Crossovers with the core cruises suggest that the nitrate data are too low. Based on this evidence, an adjustment of 1.05 was applied to the nitrate data.

Phosphate: The average of all crossovers is 1.06 and the inversion suggests a correction of 0.95 . Crossovers with the core cruises suggest that the phosphate data are too high. Based on this evidence, an adjustment of 0.95 was applied to the phosphate data.

These two adjustments increased the N/P ratio from 13.0 to 14.3 .

\section{MT19970707, cruise \#18}

Nitrate: The average of all crossovers is 0.98 and the inversion suggests a correction of 1.02. Crossovers with the core cruises suggest that the nitrate data are too low. Based on this evidence, an adjustment of 1.02 was applied to the nitrate data. 
06MT19990711, cruise \#21

Phosphate: The crossover analysis and the inversion of the adjusted data consistently suggest that this cruise needs an upward adjustment. The average of all crossovers is 0.96 and the inversion suggests an adjustment of 1.04. Based on this evidence, an adjustment of 1.04 was applied to the phosphate data.

\section{MT20010507, cruise \#23}

Phosphate: The average of all crossovers is 0.89 and the inversion suggests a correction of $\sim 1.11$. Most crossovers with the core cruises suggest that the phosphate data are too low. Based on this evidence, an adjustment of 1.11 was applied to the phosphate data.

\section{MT20010717, cruise \#25}

Phosphate: The average of all crossovers is 0.78 and the inversion suggests a correction of 1.20. The inversion of the adjusted (1.20) data suggest additional adjustment of 1.05, and the average of the crossovers is now 0.95. Based on this evidence, an adjustment of 1.25 was applied to the phosphate data.

\section{MT20021013, cruise \#28}

Silicate: The average of all crossovers (only 2) is 1.10 and the inversion suggests a correction of 0.90-0.92. Crossovers with the core cruises (A16 repeats) suggest that the silicate data are too high. Based on this evidence, an adjustment of 0.92 was applied to the silicate data.

\section{MT20040311, cruise \#32}

Phosphate: The average of all crossovers is 1.05 and the inversion suggests a correction of 0.93. Crossovers with the core cruises suggest that the phosphate data are too high. However, the crossover analysis of the adjusted (0.94) data suggests that this cruise was adjusted too much. The average of the crossovers is 0.96 and the inversion suggests an adjustment of 1.04. Based on this evidence, an adjustment of 0.97 was applied to the phosphate data.

\section{HU1992052, cruise \#37}

Phosphate: The average of all crossovers is 1.04 and the inversion suggests a correction of 0.97. Crossovers with the core cruises suggest that the phosphate data are too high. Based on this evidence, an adjustment of 0.98 was applied to the phosphate data.

\section{HU19930405, cruise \#38}

This cruise has only samples down to $1000 \mathrm{~m}$ depth, which prevent crossover analysis, and make the secondary QC difficult. The nutrient data for this cruise is not considered in the secondary QC.

\section{HU19940524, cruise \#41}

Phosphate: The average of all crossovers is 1.15 and the inversion suggests a correction of 0.89 . Crossovers with the core cruises suggest that the phosphate data are too high. Based on this evidence, an adjustment of 0.89 was applied to the phosphate data.

\section{CS19771007, cruise \#51}

This cruise has only samples down to less than $1500 \mathrm{~m}$ depth, which prevent crossover analysis, and make the secondary QC difficult. The nutrient data for this cruise is not considered in the secondary QC.

\section{CS19930510, cruise \#52}

Silicate: The average of all crossovers is 0.89 and the inversion suggests a correction of 1.06. However, due to no offset in the shallower waters and the fact that there is evidence in salinity and alkalinity that the properties of the deep water has changed, the silicate data are not considered in the secondary QC.

\section{GD19821110, cruise \#53}

Nitrate: The average of all crossovers is 0.90 and the inversion suggests a correction of 1.02-1.03. Crossovers with the core cruises suggest that the nitrate data are too low. Based on this evidence, an adjustment of 1.02 was applied to the nitrate data.

Phosphate: The average of all crossovers is 1.05 and the inversion suggests a correction of 0.96 , but with high uncertainty in the crossovers. Crossovers with the core cruises suggest that the phosphate data are too high. Based on this evidence a conservative adjustment of 0.98 was applied to the phosphate data.

\section{GD19831201, cruise \#54}

This cruise has only a few samples deeper than $1500 \mathrm{~m}$ depth, which prevent crossover analysis, and make the secondary QC difficult. The nutrient data for this cruise are not considered in the secondary QC. 


\section{GD19840218, cruise \#55}

Nitrate: The average of all the crossovers is 1.05 and the inversion suggests a correction of 0.95. Crossovers with the core cruises suggest that the nitrate data are too high. Based on this evidence, an adjustment of 0.95 was applied to the nitrate data.

Silicate: The average of all crossovers is 0.99 and the inversion suggests a correction of 0.95 . However, there are few and inconclusive crossovers with the core cruises. Additionally, natural silicate variability in Mediterranean Outflow region is too large to suggest the adjustment from the inversion. Based on this evidence no adjustment was applied to the silicate data.

\section{HE19980730, cruise \#60}

Nitrate: The average of all crossovers is 0.94 and the inversion suggests a correction of 1.04. Crossovers with the core cruise suggest that the nitrate data are too low. Based on this evidence, an adjustment of 1.07 was applied to the nitrate data.

Phosphate: The average of all crossovers is 0.88 and the inversion suggests a correction of 1.05. There is considerable scatter in the phosphate data, but crossovers with the core cruises suggest that the phosphate data are too low. Based on this evidence, the phosphate data were flagged as questionable, and are not included in the data product.

Silicate: The average of all crossovers is 0.90 and the inversion suggests a correction of 1.14 Crossovers with the core cruises suggests that the silicate data are too low. Based on this evidence, an adjustment of 1.14 was applied to the silicate data.

\section{HE20030408, cruise \#63}

Silicate: The average of all crossovers is 0.89 and the inversion suggests a correction of 1.08. Crossovers with the core cruises suggest that the silicate data are too low. Based on this evidence, an adjustment of 1.08 was applied to the silicate data.

Phosphate: The average of all crossovers is 0.90 and the inversion suggests a correction of 1.12. Crossovers with the core cruises suggest that the phosphate data are too low. Based on this evidence, an adjustment of 1.12 was applied to the phosphate data.

\section{N20031023, cruise \#69}

Phosphate: The average of all crossovers is 0.97 and the inversion suggests a correction of 1.03. Crossovers with the core cruises suggest that the phosphate data are too low. Based on this evidence, an adjustment of 1.03 was applied to the phosphate data.
32EV19910328, cruise \#71

Nitrate: The average of all crossovers is 0.95 and the inversion suggests a correction of 1.04-1.05. Crossovers with the core cruises suggest that the nitrate data are too low. Based on this evidence, an adjustment of 1.05 was applied to the nitrate data.

Silicate: The average of all crossovers is 1.099 and the inversion suggests an adjustment of 0.94 . However, the high variability of the region is recognized, and no adjustment is applied to the silicate data.

\section{RO20050111, cruise \#87}

Phosphate: The average of all crossovers is 0.96 and the inversion suggests a correction of 1.03. Crossovers with the core cruises suggest that the phosphate data are too low. Most importantly, the overlap with 33RO20030604 and 317519930704 (i.e. repeats of the A16N section) support this. Based on this evidence, an adjustment of 1.03 was applied to the phosphate data.

\section{SW20010102, cruise \#89}

This cruise has only 3 deep stations with nutrient samples, which prevent crossover analysis, and make the secondary $\mathrm{QC}$ difficult. There is however significant scatter in the nitrate/phosphate relation (Fig. 2c), which could indicate poor precision of the measurements, but could potentially reflect differences $\mathrm{N} / \mathrm{P}$ between the different hydrographic areas covered by this cruise. The nutrient data for this cruise are not considered in the secondary QC.

\section{AR19970805, cruise \#91}

Nutrient samples from this cruise were poisoned with chloroform and measured ashore. All data are from a variable region (Greenland-Scotland Ridge) and are thus difficult analyze for secondary QC.

Nitrate: The average of all crossovers is 0.95 and the inversion suggests a correction of 1.05. Crossovers with the core cruises suggest that the nitrate data are too low. Based on this evidence, an adjustment of 1.05 was applied to the nitrate data.

Phosphate: The average of all crossovers is 0.93 and the inversion suggests an adjustment of 1.05. Crossovers with the core cruises suggest that the phosphate data are too low. Based on this evidence, an adjustment of 1.04 was applied to the phosphate data.

Silicate: The average of all crossovers is 0.85 and the inversion suggests a correction of 1.14. Crossovers with the core cruises suggest that the silicate data are too low. Based on this evidence, an adjustment of 1.15 was applied to the silicate data. 


\section{A320010203, cruise \#92}

Nitrate: The average of all crossovers is 1.03 and the inversion suggests a correction of 0.97-0.98. Crossovers with the core cruises suggest that the nitrate data are too high. Based on this evidence, an adjustment of 0.98 was applied to the nitrate data.

\section{A320010322, cruise \#93}

Nitrate: The average of all crossovers is 1.04 and the inversion suggests a correction of 0.92 . Crossovers with the core cruises suggest that the nitrate data are too high, but not at the magnitude as the inversion suggests. Based on this evidence, an adjustment of 0.98 was applied to the nitrate data, in agreement with the adjustment applied to 35A320010203.

\section{TH19990712, cruise \#106,}

Phosphate: The average of all crossovers is 1.07 and the inversion suggests a correction of 0.94 . The phosphate data have only a resolution of $0.1 \mu \mathrm{mol} / \mathrm{kg}$ and crossovers with the core cruises suggest that the phosphate date are too high. Based on the large offsets, and the poor resolution of the data, the phosphate data are flagged as questionable and not included in the data product.

\section{TH20010823, cruise \#107}

Phosphate: The average of all crossovers is 1.09 and the inversion suggests a correction of 0.96. Crossovers with the core cruises suggest that the phosphate data are too high. Based on this evidence, an adjustment of 0.96 was applied to the phosphate data.

Silicate: The average of all crossovers is 0.94 and the inversion suggests a correction of 1.07. Crossovers with the core cruises suggest that the silicate data are too low. Based on this evidence, an adjustment of 1.07 was applied to the silicate data.

\section{TH20020611, cruise \#108}

Phosphate: The average of all crossovers is 1.04 and the inversions suggest a correction of 0.96. Crossovers with the core cruises suggest that the phosphate data are too high. Based on this evidence, an adjustment of 0.96 was applied to the phosphate data.

\section{TH20040604, cruise \#109}

Nitrate: The average of all crossovers is 1.04 and the inversion suggests a correction of 0.96 . Crossovers with the core cruises suggest that the nitrate data are too high. Based on this evidence, an adjustment of 0.96 was applied to the nitrate data.

Phosphate: The average of all crossovers is 0.90 and the inversion suggests a correction of 1.10. Crossovers with the core cruises suggest that the phosphate data are too low. Based on this evidence, an adjustment of 1.10 was applied to the phosphate data.

Silicate: The average of all crossovers is 1.04 and the inversion suggests a correction of 0.97 . The crossovers with the core cruises are inconclusive, but at least for the crossovers in the eastern basin, there is a clear tendency for the silicate data to be too high. Based on this evidence, an adjustment of 0.98 was applied to the silicate data.

\section{JH19920712, cruise \#130}

This cruise is conducted in the overflow region of the Greenland-Scotland Ridge. Due to the high variability in the area this cruise is not considered in the secondary QC.

\section{JH19940723, cruise \#135}

This cruise is conducted in the overflow region of the Greenland-Scotland Ridge. Due to the high variability in the area this cruise is not considered in the secondary QC.

Phosphate: The average of all crossovers and the inversion indicate the phosphate values are high with about 6-10\%. The N/P relation reveals an unusually large negative intercept that seems to be due to problems with the phosphate rather than nitrate. Since regular secondary QC is difficult in this region and the phosphate values can not be soundly adjusted, they were flagged as "poor" and are not included in the data product.

\section{PE20000926, cruise \#152}

Phosphate: The average of all crossovers is 1.03 and the inversion suggests a correction of 0.96 . Crossovers with the core cruises suggest that the phosphate data are too high. Based on this evidence, an adjustment of 0.96 was applied to the phosphate data.

\section{TR19890731, cruise \#153}

Nitrate: The average of all crossovers is 1.04 and the inversion suggests a correction of 0.97 . Crossovers with the core cruises suggest that the nitrate data are too high. Based on this evidence, an adjustment of 0.96 was applied to the nitrate data.

Phosphate: The average of all crossovers is 1.00 , but with large uncertainty, and the inversion suggests a correction of 1.07. Crossovers with the core cruises suggest that the phosphate data are of poor quality. Based on this evidence, the 
phosphate data are flagged questionable and are not included in the data product.

\section{TR19900417, cruise \#154}

Phosphate: The average of all crossovers is 1.09 and the inversion suggests a correction of 0.96. Crossovers with the core cruises suggest that the phosphate data are too high. Based on this evidence, an adjustment of 0.96 was applied to the phosphate data.

\section{TR19910408, cruise \#156}

Phosphate: The average of all crossovers is 1.08 and the inversion suggests a correction of 0.91-0.93. Crossovers with the core cruises suggest that the phosphate data are too high. Based on this evidence, an adjustment of 0.93 was applied to the phosphate data.

\section{SL19881117, cruise \#158}

This cruise has no samples deeper than $1200 \mathrm{~m}$ depth, which prevent crossover analysis, and make the secondary QC difficult. The nutrient data for this cruise are not considered in the secondary QC.

\section{AB19900528, cruise \#159}

Nitrate: The average of all crossovers is 0.92 and the inversion suggests a correction of 1.10-1.11. Crossovers with the core cruises suggest that the nitrate data are too low. Based on this evidence, an adjustment of 1.11 was applied to the nitrate data.

Silicate: The average of all crossovers is 0.93 , but with large variability, and the inversion suggests a correction of 1.16. Crossovers with the core cruises suggest that the silicate data are not biased. There is large variability in the data and few data points to base the adjustments on. Therefore the silicate data are not considered in the secondary QC.

\section{AB19910501, cruise \#160}

Silicate: The average of all crossovers is 1.05 and the inversion suggests a correction of 0.97 . Crossovers with the core cruises suggest that the silicate data are too high. Based on this evidence, an adjustment of 0.97 was applied to the silicate data.

\section{AB19910614, cruise \#161}

This cruise has no deep samples, which prevent crossover analysis, and make the secondary QC difficult. The nutrient data for this cruise are not considered in the secondary QC.

\section{AB19910712, cruise \#162}

This cruise has few deep samples, all in a variable area.

Nitrate: The nitrate data are not considered due to the few deep nitrate samples, even though the average of all crossovers is 0.94 and the inversion suggest a correction of 1.06 .

Silicate: The average of all crossovers is 1.13 and the inversions suggest a correction of 0.90 . Crossovers with the core cruises suggest that the silicate data are too high. Based on this evidence, an adjustment of 0.90 was applied to the silicate data

\section{AB20050501, cruise \#164}

Nitrate: The average of all crossovers is 1.03 and the inversion suggests a correction of 0.98 . Crossovers with the core cruises suggest that the nitrate data are too high. Based on this evidence, an adjustment of 0.98 was applied to the nitrate data.

Phosphate: The average of all crossovers is 1.04 and the inversion suggests a correction of 0.98 . Crossovers with the core cruises suggest that the phosphate data are too high. Based on this evidence, an adjustment of 0.97 was applied to the phosphate data.

Silicate: The average of all crossovers is 1.12 and the inversions suggest a correction of 0.93 . Crossovers with the core cruises suggest that the silicate data are too high. Based on this evidence, an adjustment of 0.93 was applied to the silicate data.

\section{DI19890511, cruise \#165}

This cruise has no deep samples, which prevent crossover analysis, and make the secondary QC difficult. The nutrient data for this cruise are not considered in the secondary QC.

\section{DI19890612, cruise \#166}

Only few stations for this cruise have deep nutrient data.

Nitrate: The average of all crossovers is 0.96 , but with high standard deviations, and the inversions suggest a correction of 1.10. Crossovers with the core cruises suggest that the nitrate data are of poor quality. Based on this evidence, the nitrate data was flagged as questionable, and are not included in the data product.

Silicate: The average of all crossovers is 0.92 , but with large standard deviations, and the inversion suggests a correction of 1.10. Crossovers with the core cruises suggest that the silicate data are of low quality. Based on this evidence, the silicate data were flagged as questionable, and are not included in the data product. 


\section{DI19890716, cruise \#167}

Nitrate: The average of all crossovers is 0.89 and the inversion suggests a correction of 1.17. Crossovers with the core cruises suggest that the nitrate data are much too low. Based on the high offset, the nitrate data were flagged as questionable, and are not included in the data product.

Phosphate: The average of all crossovers is 1.09 , but with large standard deviations, and the inversion suggests a correction of 0.94. Crossovers with the core cruises suggest that the phosphate data are too high and of poor quality. Based on this evidence, the phosphate data was flagged as questionable, and are not included in the data product.

Silicate: The average of all crossovers is 0.99 and the inversion suggests a correction of 1.06. Crossovers with the core cruises suggest that the silicate data are too low, but the results are inconclusive. The data seems to be of low precision, in addition to high variability in the area. Based on this evidence no adjustment was applied to the silicate data.

\section{DI19900425, cruise \#168}

This cruise has no deep samples, which prevent crossover analysis, and make the secondary QC difficult. The nutrient data for this cruise are not considered in the secondary QC.

\section{DI19900515, cruise \#169}

This cruise has only few deep samples, which prevent crossover analysis, and make the secondary QC difficult. The nutrient data for this cruise are not considered in the secondary QC.

\section{DI19900612, cruise \#170}

Nitrate: The average of all crossovers is 1.09 and the inversion suggest a correction of 0.92-0.93. Crossovers with the core cruises suggest that the nitrate data are too high. Based on this evidence, an adjustment of 0.95 was applied to the nitrate data.

Phosphate: The average of all crossovers is 0.90 and the inversion suggests a correction of 1.09. Crossovers with the core cruises suggest that the nitrate data are too low. Based on this evidence, an adjustment of 1.10 was applied to the phosphate data.

Silicate: The average of all crossovers is 1.47 , but with very different offsets for the crossovers. There are too few deep silicate data to properly suggest a correction, and due to the large offsets in the few available crossovers, the silicate data were flagged as questionable and are not included in the data product.

\section{DI19970807, cruise \#171}

Nutrients for this cruise were analyzed by Gouretski and Jancke (2001) who determined biases for nitrate, phosphate and silicate of $-0.58,0.115$ and $1.0 \mu \mathrm{mol} / \mathrm{kg}$ respectively.

Phosphate: The crossover analysis and the inversion results of the adjusted data suggest that this cruise needs an adjustment. The judgment is difficult due to relatively large scatter in the data, but is facilitated by the large number of crossovers. The average of the crossovers is 1.04 and the inversion suggests a correction of 0.97 . Based on this evidence, an adjustment of 0.97 was applied to the phosphate data.

\section{DI20040404, cruise \#173}

Nitrate: The average of all crossovers is 1.03 and the inversion suggests a correction of 0.96-97. Crossovers with the core cruises suggest that the nitrate data are too high. Based on this evidence, an adjustment of 0.97 was applied to the nitrate data.

Silicate: The average of all crossovers is 1.05 and the inversion suggests a correction of 0.97 . Crossovers with the core cruises suggest that the silicate data are too high. Based on this evidence, an adjustment of 0.98 was applied to the silicate data.

\section{IrmingerSea, cruise \#185}

This time series does not have any samples deeper than $\sim 1000 \mathrm{~m}$, and is situated in a variable region, which prevent crossover analysis, and make the secondary QC difficult. The nutrient data for this cruise are not considered in the secondary QC, for details see Olafsson et al. (2009).

\section{OMEX1NA, cruise \#187}

This entry represents a number of field campaigns with nutrients measured by 3 main groups. Significant offsets between these measurements have been reported (Hydes et al., 2001).

\section{Reference cruises}

\section{N19961102}

This cruise is not part of CARINA, but is included as a reference cruise. This cruise is included in GLODAP, but no adjustments were suggested for the nutrient data.

Phosphate: The average of all crossovers is 1.05 and the inversion suggests a correction of 0.94. Crossovers with the core cruises suggest a slightly smaller correction. Based on this evidence we suggest an adjustment of 0.96 to the phosphate data. 


\section{HE19920714}

This cruise is not part of CARINA, but is included as a reference cruise. Nutrients for this cruise were analyzed by Gouretski and Jancke (2001) who determined biases for nitrate, phosphate and silicate of $0.34,0.003$ and $1.9 \mu \mathrm{mol} / \mathrm{kg}$, respectively.

Phosphate: The average of all crossovers is 0.95 and the inversion suggests a correction of 1.05-1.10. Crossovers with the core cruises suggest that the phosphate data are too low. This is also true for the two repeats of this section in 1998 and 2004. The phosphate data for this cruise show a considerable amount of scatter. Based on this evidence, we suggest an adjustment of 1.05 for phosphate, but we also suggest that the phosphate data are flagged as questionable.

Silicate: The average of all crossovers is 1.05 and the inversion suggests a correction of $0.95-0.96$. Crossovers with the core cruises suggest that the silicate data are too high. This is also true for the two repeats of this section in 1998 and 2004. Based on this evidence, we suggest an adjustment of 0.97 for the silicate data.

\section{4}

This cruise is included in GLODAP and is only in CARINA for reference. Nutrients for this cruise were analyzed by Gouretski and Jancke (2001) who determined biases for nitrate, phosphate and silicate of $0.0(0.0),-0.038(-0.032)$ and $-0.4(-2.6) \mu \mathrm{mol} / \mathrm{kg}$, respectively (station range is $1: 37$ (38:83)).

Silicate: The average of all crossovers is 0.97 and the inversion suggests a correction of 1.03. Crossovers with the core cruises suggest that the silicate data are too low. Based on this evidence, we suggest an adjustment of 1.03 to the silicate data.

\section{4}

This cruise is included in GLODAP and is only in CARINA for reference. Nutrients for this cruise were analyzed by Gouretski and Jancke (2001) who determined biases for nitrate, phosphate and silicate of $0.06,0.024$ and $1.6 \mu \mathrm{mol} / \mathrm{kg}$, respectively.

Silicate: The final inversion using the adjusted data provided stronger evidence that an adjustment was motivated. The Southern Ocean and Atlantic groups agreed to suggest an adjustment of 0.98 to this cruise.

For the reference cruises $316 \mathrm{~N} 19970815$ and 316N19970717 the CARINA group recommends no adjustments to the nutrient data and only small adjustments are applied to the GLODAP data.

\section{Data access}

The whole CARINA database set is published at http://cdiac. ornl.gov/oceans/CARINA/Carina_inv.html. It contains 188 individual cruise files in comma-separated, WHPO exchange format. Condensed metadata are contained in the header of each data file. In addition, the CARINA database contains three merged, comma-separated data files with the data products. These files are divided into the three geographical regions of CARINA. Adjustments are only applied to the merged data products, not to the individual cruise files. No special software is needed to access the data, but software for MATLAB users is offered to facilitate reading of the data.

\section{Summary}

This report describes the secondary QC of the nutrient data for the Atlantic Ocean part of the CARINA data base. Out of a total of 188 cruise entries in the CARINA database, 98 were conducted in the Atlantic Ocean and of these 84 cruises report nitrate values, 79 silicate, and 78 phosphate. Adjustments were applied to 17 of the cruises for nitrate, 25 for phosphate, and 16 for silicate. Where no adjustment could be determined, this was most commonly due to sparse data coverage, and applied to 15 of the cruises for nitrate, 11 of the cruises for phosphate, and 12 of the cruises for silicate. Data were flagged as poor, i.e. data are not included in the data product, for 2 cruises for nitrate, 6 cruises for phosphate, and 2 cruises for silicate. Based on our analysis we estimate the internal accuracy of the CARINA-ATL nutrient data to be: nitrate $1.5 \%$; phosphate $2.6 \%$; silicate $3.1 \%$.

Acknowledgements. This work has been performed and funded as part of the EU project CarboOcean (Project 511176). Additional support from the International Ocean Carbon Coordination Project IOCCP (Maria Hood) and the Hanse Institute for Advanced Study (HWK Delmenhorst, Germany) are gratefully acknowledged. R. M. Key was additionally supported by NOAA grant NA08OAR4320752 and NA08OAR4310820; and P. J. Brown was additionally supported by NERC Award NER/S/A/2004/12255. Without the dedication of all investigators and analysts who performed measurements, sometimes under adverse conditions, and contributed their data to the CARINA data base, this project would not have been possible.

Edited by: A. Olsen 


\section{References}

Aminot, A. and Kirkwood, D. S.: Report on the results of the fifth ICES Intercomparison Exercise for Nutrients in Seawater, ICES Cooperative Research Report No. 213, 79 pp., 1995.

Aoyama M., Barwell-Clarke, J., Becker, S., Blum, M., Braga, E. S., Coverly, S. C., Czobik, E., Dahllof, I., Dai, M. H., Donnell, G. O., Engelke, C., Gong, G. C., Gi-Hoon Hong, Hydes, D. J., Jin, M. M., Kasai, H., Kerouel, R., Kiyomono, Y., Knockaert, M., Kress, N., Krogslund, K. A., Kumagai, M., Leterme, S., Yarong Li, Masuda, S., Miyao, T., Moutin, T., Murata, A., Nagai, N., Nausch, G., Ngirchechol, M. K., Nybakk, A., Ogawa, H., van Ooijen, J., Ota, H., Pan, J. M., Payne, C., Pierre-Duplessix, O., Pujo-Pay, M., Raabe, T., Saito, K., Sato, K., Schmidt, C., Schuett, M., Shammon, T. M., Sun, J., Tanhua, T., White, L., Woodward, E. M. S., Worsfold, P., Yeats, P., Yoshimura, T., Youenou, A., and Zhang, J. Z.: 2006 Intercomparison Exercise for Reference Material for Nutrients in Seawater in a Seawater Matrix, Technical Reports of the Meteorological Research Institute No. 58, 104 pp., 2008.

Hydes, D. J., Le Gall, A. C., Miller, A. E. J., Brockmann, U., Raabe, T., Holley, S., Alvarez-Salgado, X., Antia, A., Balzer, W., Chou, L., Elskens, M., Helder, W., Joint, I., and Orren, M.: Supply and demand of nutrient and dissolved organic matter at and across the NW European shelf break in relation to hydrography and biogeochemical activity, Deep-Sea Res. Pt. II, 48(14/15), 3023-3047, 2001.

Gouretski, V. V. and Jancke, K.: Systematic errors as the cause for an apparent deep water property variability: global analysis of the WOCE and historical hydrographic data, Prog. Oceanogr., 48, 337-402, 2001.

Key, R. M., Kozyr, A., Sabine, C. L., Lee, K., Wanninkhof, R., Bullister, J. L., Feely, R. A., Millero, F. J., Mordy, C., and Peng, T. H.: A global ocean carbon climatology: Results from Global Data Analysis Project (GLODAP), Global Biogeochem. Cy., 18, GB4031, doi:1029/2004GB002247, 2004.
Key, R. M., Tanhua, T., Olsen, A., Hoppema, M., Jutterström, S., Schirnick, C., van Heuven, S., Lin, X., Wallace, D. W. R., and Mintrop, L.: The CARINA data synthesis project: Introduction and overview, Earth Syst. Sci. Data Discuss., submitted, 2009.

Olafsson, J., Olafsdottir, S. R., Benoit-Cattin, A., and Takahashi, T.: The Irminger Sea and the Iceland Sea time series measurements of sea water carbon and nutrient chemistry 1983-2006, Earth Syst. Sci. Data Discuss., 2, 477-492, 2009, http://www.earth-syst-sci-data-discuss.net/2/477/2009/.

Redfield, A. C., Ketchum, B. H., and Richards, F. A.: The influence of organisms on the composition of seawater, in: The Sea, edited by: Hill, M. N., Interscience, 26-77, 1963.

Swift, J.: A guide to submitting CTD/hydrographic/tracer data and associated documentation to the CLIVAR and carbon hydrographic data office, ver. 4/22/08, UCSD Scripps Institution of Oceanography, http://whpo.ucsd.edu/CCHDO DataSubmitGuide.pdf, 37 pp., 2008.

Tanhua, T., Steinfeldt, R., Key, R. M., Brown, P., Gruber, N., Wanninkhof, R., Perez, F., Körtzinger, A., Velo, A., Schuster, U., van Heuven, S., Bullister, J. L., Stendardo, I., Hoppema, M., Olsen, A., Kozyr, A., Pierrot, D., Schirnick, C., and Wallace, D. W. R.: Atlantic Ocean CARINA data: overview and salinity adjustments, Earth Syst. Sci. Data Discuss., 2, 241-280, 2009a, http://www.earth-syst-sci-data-discuss.net/2/241/2009/.

Tanhua, T., van Heuven, S., Key, R. M., Velo, A., Olsen, A., and Schirnick, C.: Quality control procedures and methods of the CARINA database, Earth Syst. Sci. Data Discuss., 2, 205-240, 2009b, http://www.earth-syst-sci-data-discuss.net/2/205/2009/. 